\title{
Feedback of ATP Measurement as a Tool for Reducing Environmental Contamination in Hospitals in the Dutch/Belgian Border Area.
}

Andreas van Arkel ( $\nabla$ a.vanarkel@etz.nl)

Elisabeth-TweeSteden Ziekenhuis https://orcid.org/0000-0003-3391-9200

Ina Willemsen

Amphia Ziekenhuis Locatie Molengracht

Linda Kilsdonk-Bode

Amphia Ziekenhuis Locatie Molengracht

Sindy Vlamings-Wagenaars

Elisabeth-TweeSteden Ziekenhuis

Anne van Oudheusden

Elisabeth-TweeSteden Ziekenhuis

Pascal De Waegemaeker

Universitair Ziekenhuis Gent

Isabel Leroux-Roels

Universitair Ziekenhuis Gent

Martine Verelst

Katholieke Universiteit Leuven Universitaire Ziekenhuizen Leuven

Evelien Maas

ZorgSaam

Anita van Oosten

Admiraal De Ruyter Ziekenhuis

Patricia Willemse

Elkerliek Ziekenhuis

\section{Esther van Asselen}

Elkerliek Ziekenhuis

Ella Klomp-Berens

Maastricht Universitair Medisch Centrum+

Karen Franssen

Maastricht Universitair Medisch Centrum+

Elise Van Cauwenberg

Universitair Ziekenhuis Antwerpen

Valentijn Schweitzer 
Universitair Medisch Centrum Utrecht

Jan Kluytmans

Amphia Ziekenhuis Locatie Molengracht

Research

Keywords: ATP measurement, fomite, reduction, surface contamination, cleaning

Posted Date: June 4th, 2020

DOI: https://doi.org/10.21203/rs.3.rs-31965/v1

License: (c) (i) This work is licensed under a Creative Commons Attribution 4.0 International License. Read Full License

Version of Record: A version of this preprint was published at International Journal For Quality In Health Care on January 1st, 2021. See the published version at https://doi.org/10.1093/intqhc/mzab153. 


\section{Abstract}

Background \& objective: The objective of this study was to determine the effect from feedback of ATP measurements on environmental contamination within hospitals in the Dutch/Belgian border area.

Setting: Standardized ATP measurements were conducted in 9 hospitals on pre-defined fomites. Four different fomite groups were defined: medical devices, patient bound materials, ward bound materials and sanitary items. ATP results were reported in relative light units (RLU), RLU >1000 was considered as "not clean." Two rounds of ATP measurements were conducted. After the first round of ATP measurements, results were provided to the wards. There were no structured cleaning interventions implemented. The second round of ATP measurements was performed one year later. The amount of surface contamination before and after the feedback were compared.

Results: In total 1923 ATP measurements were performed. Before feedback 960 ATP measurements were conducted and after feedback 963. The overall median reduction in RLU was 381 ( $p<0.001)$, from 568 before feedback to 187 afterwards. In each hospital there was a reduction of the median RLU after feedback.

Conclusion/discussion: Substantial reductions in RLU values were found after feedback of ATP measurements. Feedback of ATP measurements was associated with a major reduction of surface contamination in hospitals.

\section{Materials \& Methods}

\section{Setting}

As part of a multicenter project in the Dutch/Belgian border area, the i-4-1-Health project, standardized ATP measurements were conducted in 9 hospitals (3 Belgian university hospitals, 1 Dutch university hospital, 3 Dutch teaching hospitals and 2 Dutch general hospitals). ATP measurements were conducted on different hospital wards, ranging from 2 wards up to 4 wards per hospital, depending on the hospital size. In each hospital, ATP measurements were conducted on a surgical ward, an internal medicine ward and if applicable two other medical wards. When ATP measurements were conducted on more than 2 wards a selection was made from the medical specialties urology, cardiology, orthopedic surgery, pulmonology and/or geriatrics. For the data analysis medical specialties were merged into two groups: surgical specialties and non-surgical specialties. On each ward, ATP measurements were performed on a selection of 30 pre-defined fomites. ${ }^{9}$ These fomites were classified into 4 different groups: medical devices, patient bound materials, sanitary items and ward bound materials. Fomites were chosen based on the following criteria: frequently touched by nursing staff or patients or being in the direct vicinity of patients or high risk surfaces (e.g. tabletop for medication preparation). ATP measurements were performed at two points in time, one year apart each other. After the first round of ATP measurements feedback was given to the nursing and cleaning staff. The ATP results were provided to the ward by an infection control practitioner. There were no structured cleaning interventions planned as part of the project. Each hospital was free to 
implement any cleaning interventions. The effect of the feedback was measured in a second round of ATP measurements.

\section{Atp Measurements \& Rlu Breakpoints}

The Clean-Trace NG Luminometer (3M, Zoeterwoude, the Netherlands) was used for the ATP measurements, results were reported in RLU. ATP measurements were conducted by trained and validated researchers working at the department of infection control of the corresponding hospital. The RLU $<1000$ breakpoint for cleanliness was defined for measuring a fomite at a random point during the day as described in van Arkel, el al. ${ }^{9}$ An RLU value above 1000 RLU was categorized as unclean or intermediate, above 3000 RLU as dirty.

\section{Statistical Methods}

All data were analyzed with Statistical Package for Social Science software (SPSS; IBM Corp., Armonk, New York, US; version 25) and R (R Foundation, New Zealand, R version 3.6.2). Adjusted relative risks (ARRs) were calculated based on the differences in the occurrence of "not clean" fomites (RLU > 1000) between the two time periods and analysed using mixed effects Poisson regression models using a log link with a random intercept and random slope per hospital. Differences between RLU values were analysed log transformed using mixed effect linear regression models with a random intercept and fixed slope per hospital. Adjusted models were corrected for hospital, medical specialty and surface category.

\section{Results}

In total 1923 ATP measurements were performed. Before feedback 960 ATP measurements were conducted and after feedback 963 . Per hospital 120 up to 246 ATP measurements were performed, depending on the hospital size.

The median RLU before feedback was 568 RLU and after feedback 187 RLU, resulting in a reduction of $381 \mathrm{RLU}(\mathrm{p}<0.001)$ (Fig. 1). Of all measurements before feedback $37.7 \%(362 / 960)$ were considered as "not clean" (RLU > 1000), after feedback 13.1\% (126/963) were considered as "not clean."

The differences in RLU between the first and second round per hospital are visualized in Fig. 2. The median RLU value per hospital before feedback ranged from 279 to 2137 (Fig. 2). After feedback the median RLU value per hospital ranged from 83 to 830 (Fig. 2). Each hospital showed a reduction in median RLU between the first and second round of measurements.

Per medical specialty between 60 and 538 ATP measurements were conducted. The median RLU value before feedback was 627 in the surgical specialty group and 546 in the non-surgical specialty group. After feedback the median RLU value was 200 in the surgical specialty group and 172 in the non-surgical specialty group. 
Per fomite group 320 up to 640 ATP measurements were conducted: 627 ATP measurements in the medical devices group, 320 ATP measurements in the patient bound materials group, 640 ATP measurements in the sanitary items group and 336 ATP measurements in the ward bound materials group. The differences in RLU between rounds of the fomite groups is visualized in Fig. 3. The median RLU value in the patient bound materials group was reduced from 931 to 224 , in the ward bound materials group from 659 to 293, in the medical devices from 651 to 187 and in the sanitary items from 396 to 131 , before and after feedback respectively.

Predictors for the more frequent occurrence of "not clean" (RLU > 1000) surfaces between the first and second round of measurements for the different groups are visualized in Table 1, significant differences are highlighted. 
Table 1

Univariable and multivariable analysis of median differences and percentages of "not clean" (RLU $>1000$ ) items per round, with adjusted relative risks. Significant differences in bold $(p<0.05)$. Adjusted models are corrected for hospital, medical specialty and surface category.

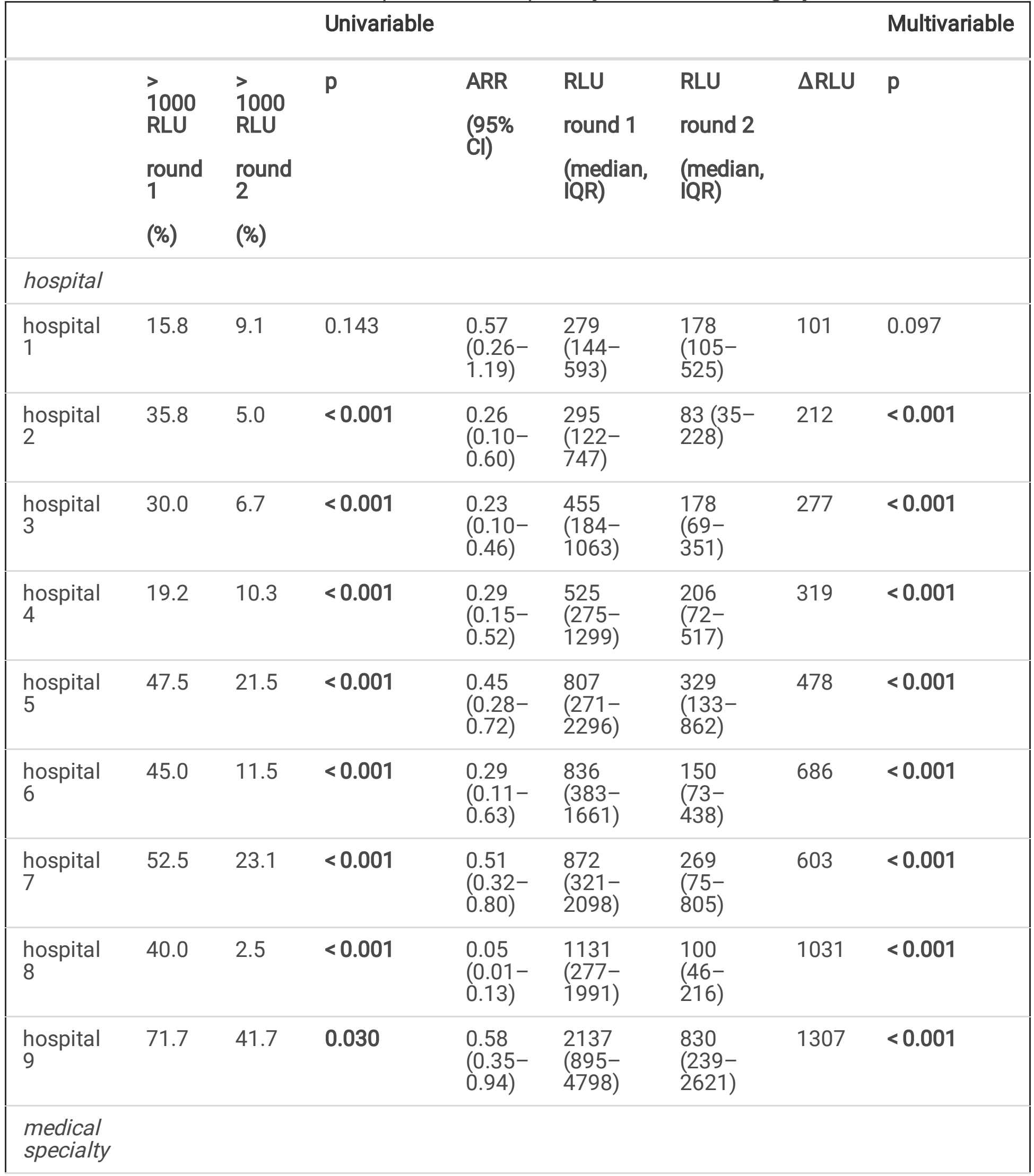




\begin{tabular}{|c|c|c|c|c|c|c|c|c|}
\hline & & & Univariable & & & & & Multivariable \\
\hline surgical & 40.7 & 13.4 & $<0.001$ & $\begin{array}{l}0.33 \\
(0.24- \\
0.44)\end{array}$ & $\begin{array}{l}627 \\
(241- \\
1592)\end{array}$ & $\begin{array}{l}200 \\
(72- \\
553)\end{array}$ & 427 & $<0.001$ \\
\hline $\begin{array}{l}\text { non- } \\
\text { surgical }\end{array}$ & 35.1 & 12.8 & $<0.001$ & $\begin{array}{l}0.37 \\
(0.27- \\
0.48)\end{array}$ & $\begin{array}{l}546 \\
(217- \\
1534)\end{array}$ & $\begin{array}{l}172 \\
(69- \\
474)\end{array}$ & 374 & $<0.001$ \\
\hline \multicolumn{9}{|l|}{$\begin{array}{l}\text { surface } \\
\text { category }\end{array}$} \\
\hline $\begin{array}{l}\text { sanitary } \\
\text { items }\end{array}$ & 29.4 & 11.6 & $<0.001$ & $\begin{array}{l}0.39 \\
(0.26- \\
0.56)\end{array}$ & $\begin{array}{l}396 \\
(152- \\
1324)\end{array}$ & $\begin{array}{l}131 \\
(47- \\
339)\end{array}$ & 265 & $<0.001$ \\
\hline $\begin{array}{l}\text { patient } \\
\text { bound } \\
\text { materials }\end{array}$ & 47.5 & 15.0 & $<0.001$ & $\begin{array}{l}0.31 \\
(0.19- \\
0.48)\end{array}$ & $\begin{array}{l}931 \\
(344- \\
2454)\end{array}$ & $\begin{array}{l}224 \\
(74- \\
641)\end{array}$ & 707 & $<0.001$ \\
\hline $\begin{array}{l}\text { ward } \\
\text { bound } \\
\text { materials }\end{array}$ & 40.6 & 14.2 & $<0.001$ & $\begin{array}{l}0.34 \\
(0.21- \\
0.54)\end{array}$ & $\begin{array}{l}659 \\
(260- \\
1641)\end{array}$ & $\begin{array}{l}293 \\
(121- \\
597)\end{array}$ & 366 & $<0.001$ \\
\hline $\begin{array}{l}\text { medical } \\
\text { devices }\end{array}$ & 38.4 & 13.0 & $<0.001$ & $\begin{array}{l}0.34 \\
(0.23- \\
0.48)\end{array}$ & $\begin{array}{l}651( \\
267- \\
1474)\end{array}$ & $\begin{array}{l}187 \\
(72- \\
525)\end{array}$ & 464 & $<0.001$ \\
\hline total & 37.7 & 13.1 & $<0.001$ & $\begin{array}{l}0.35 \\
(0.28- \\
0.42)\end{array}$ & $\begin{array}{l}568 \\
(227- \\
1555)\end{array}$ & $\begin{array}{l}187 \\
(70- \\
514)\end{array}$ & 381 & $<0.001$ \\
\hline
\end{tabular}

\section{Discussion}

ATP measurements can be used as a fast and objective approach to visualize the level of environmental contamination in hospitals. By using ATP measurements as feedback for nursing staff and cleaning staff, surface contamination can be reduced significantly.

The results of the ATP measurements increased interest and motivation for cleaning amongst the nursing and cleaning staff. We observed repeatedly that nursing staff voluntary measured different surfaces on the ward to get insight into surface contamination and consequently improved cleaning of these surfaces. Previous research has shown that performing ATP measurements has a beneficial effect on cleaning on hospital wards, by having an effect on multiple factors e.g. motivation of hospital staff for cleaning surfaces, giving insight into contamination of different surfaces/groups of fomites and giving a quantifiable outcome of measurement. ${ }^{6,7}$

Feedback of ATP measurements to nursing and cleaning staff seems to be an effective method to improve cleaning of hospital wards. Moreover, previous research has shown that cleaning can be improved by implementing relatively simple changes in the cleaning protocol. ${ }^{1}$ Within this study each 
hospital was free to implement cleaning interventions. These interventions included defining cleaning responsibilities per fomite, educational sessions for cleaning staff and/or introduction of new cleaningwipes. In some hospitals it was indicated that there were no cleaning interventions implemented.

For this study RLU thresholds were copied from a previous study. ${ }^{10}$ Different studies have recommended an RLU threshold for cleanliness at 250-500 RLU, however this threshold is intended for measurement (almost) directly after cleaning. ${ }^{1,3,11,12,13,14}$ Within this study RLU thresholds for conducting ATP measurements at a random point in time were used. The goal of this study was to improve cleaning based on feedback from ATP measurements. By using above described thresholds feedback could be given in an easy to visualize way.

During this study, important improvements in hospital cleanliness were observed. Considering the size of the improvement and that it was observed in all centers, it is plausible that these improvements can be contributed to feedback from the ATP measurements. However, it is unknown how long this effect will be maintained. To obtain a sustainable effect, repeated measurements over time will probably be needed. Indeed, other studies have found a washout effect after ATP measurement was ceased. ${ }^{15}$ In general, a quality program is characterized by repeated measurements and subsequent actions to improve the result. As such, ATP measurements should be integrated in a quality system for environmental cleaning.

Within three hospitals there was an outbreak with vancomycin-resistant enterococci (VRE) between the first and second round of ATP measurements. Consequently, there was a better focus on cleaning on the affected hospital wards. A part of the decrease in RLU values could be explained by the cleaning measures implemented during these VRE outbreaks. However, a significant decrease in environmental contamination was found in almost all hospitals, indicating that feedback from ATP measurements still has a beneficial effect on hospital cleanliness in general.

\section{Conclusion}

Substantial differences in RLU values were found after feedback of ATP measurements. The second round of measurements showed significantly lower median RLU values in all groups (hospitals, surface categories and medical specialties), together with significantly lower percentages for "not clean" surfaces $(R L U>1000)$ in all groups. These findings suggest that feedback of ATP measurements, presented in a way that is easy to understand, has a beneficial effect on cleaning in general. Furthermore, ATP measurements give insight into specific areas with a high level of environmental contamination to guide specific interventions.

\section{Declarations}

\section{Ethics approval and consent to participate}

Not applicable. 


\section{Consent for publication}

Not applicable.

\section{Availability of data and materials}

As agreed within the i-4-1-Health consortium, the i-4-1-Health datasets will be made available no earlier than December 31st, 2020 and no later than December 31st, 2024, in accordance with the FAIR (Findable, Accessible, Interoperable and Reusable) data principles. ${ }^{16}$

\section{Competing interests}

The authors declare that they have no competing interests.

\section{Funding}

The i-4-1-Health project was financed by the Interreg V Flanders-The Netherlands program, the cross-border cooperation program with financial support from the European Regional Development Fund (ERDF). Additional financial support was received from the Dutch Ministry of Health, Welfare and Sport, the Dutch Ministry of Economic Affairs, the Province of Noord-Brabant, the Belgian Department of Agriculture and Fisheries, the Province of Antwerp and the Province of East-Flanders. ATP luminometers and ATP surface swabs were provided by $3 \mathrm{M}$. The authors are free to publish the results from the project without interference from the funding bodies or $3 \mathrm{M}$.

\section{Authors' contributions}

Andreas van Arkel was responsible for data analysis and writing of the manuscript. The manuscript was judged by Ina Willemsen, Jan Kluytmans, Pascal De Waegemaeker, Isabel Leroux-Roels and Martine Verelst. Sindy Vlamings-Wagenaars, Anne van Oudheusden, Pascal De Waegemaeker, Martine Verelst, Evelien Maas, Anita van Oosten, Patricia Willemse, Esther van Asselen, Ella Klomp-Berens, Karen Franssen and Elise Van Cauwenberg were responsible for collection of the data. All authors read and approved the final manuscript.

\section{Acknowledgements}

We are grateful to the infection control practitioners in the participating hospitals for their contribution to the collection of the epidemiological data.

i-4-1-Health Study Group

Lieke van Alphen (Maastricht University Medical Center+, Maastricht, the Netherlands), Nicole van den Braak (Avans University of Applied Sciences, Breda, the Netherlands), Caroline Broucke (Agency for Care 
and Health, Brussels, Belgium), Anton Buiting (Elisabeth-TweeSteden Hospital, Tilburg, the Netherlands), Liselotte Coorevits (Ghent University Hospital, Ghent, Belgium), Sara Dequeker (Agency for Care and Health, Brussels, Belgium and Sciensano, Brussels, Belgium), Jeroen Dewulf (Ghent University, Ghent, Belgium), Wouter Dhaeze (Agency for Care and Health, Brussels, Belgium), Bram Diederen (ZorgSaam Hospital, Terneuzen, the Netherlands), Helen Ewalts (Regional Public Health Service Hart voor Brabant, Tilburg, the Netherlands), Herman Goossens (University of Antwerp, Antwerpen, Belgium and Antwerp University Hospital, Antwerp, Belgium), Inge Gyssens (Hasselt University, Hasselt, Belgium), Casper den Heijer (Regional Public Health Service Zuid-Limburg, Heerlen, the Netherlands), Christian Hoebe (Maastricht University Medical Center+, Maastricht, the Netherlands and Regional Public Health Service Zuid-Limburg, Heerlen, the Netherlands), Casper Jamin (Maastricht University Medical Center+, Maastricht, the Netherlands), Patricia Jansingh (Regional Public Health Service Limburg Noord, Venlo, the Netherlands), Jan Kluytmans (Amphia Hospital, Breda, the Netherlands and University Medical Center Utrecht, Utrecht University, Utrecht, the Netherlands), Marjolein Kluytmans-van den Bergh (Amphia Hospital, Breda, the Netherlands and University Medical Center Utrecht, Utrecht University, Utrecht, the Netherlands), Stefanie van Koeveringe (Antwerp University Hospital, Antwerp, Belgium), Sien De Koster (University of Antwerp, Antwerp, Belgium), Christine Lammens (University of Antwerp, Antwerp, Belgium), Isabel LerouxRoels (Ghent University Hospital, Ghent, Belgium), Hanna Masson (Agency for Care and Health, Brussel, Belgium), Ellen Nieuwkoop (Elisabeth-TweeSteden Hospital, Tilburg, the Netherlands), Anita van Oosten (Admiraal De Ruyter Hospital, Goes, the Netherlands), Natascha Perales Selva (Antwerp University Hospital, Antwerp, Belgium), Merel Postma (Ghent University, Ghent, Belgium), Stijn Raven (Regional Public Health Service West-Brabant, Breda, the Netherlands), Veroniek Saegeman (University Hospitals Leuven, Leuven, Belgium), Paul Savelkoul (Maastricht University Medical Center+, Maastricht, the Netherlands), Annette Schuermans (University Hospitals Leuven, Leuven, Belgium), Nathalie Sleeckx (Experimental Poultry Centre, Geel, Belgium), Krista van der Slikke (Regional Public Health Service Zeeland, Goes, the Netherlands), Arjan Stegeman (Utrecht University, Utrecht, the Netherlands), Tijs Tobias (Utrecht University, Utrecht, the Netherlands), Paulien Tolsma (Regional Public Health Service Brabant Zuid-Oost, Eindhoven, the Netherlands), Jacobien Veenemans (Admiraal De Ruyter Hospital, Goes, the Netherlands), Dewi van der Vegt (PAMM Laboratory for Pathology and Medical Microbiology, Veldhoven, the Netherlands), Martine Verelst (University Hospitals Leuven, Leuven, Belgium), Carlo Verhulst (Amphia Hospital, Breda, the Netherlands), Pascal De Waegemaeker (Ghent University Hospital, Ghent, Belgium), Veronica Weterings (Amphia Hospital, Breda, the Netherlands), Clementine Wijkmans (Regional Public Health Service Hart voor Brabant, Tilburg, the Netherlands), Patricia Willemse-Smits (Elkerliek Hospital, Helmond, the Netherlands), Ina Willemsen (Amphia Hospital, Breda, the Netherlands.)

\section{References}

1. Griffith CJ, Obee P, Cooper RA, Burton NF, Lewis M. The effectiveness of existing and modified cleaning regimens in a Welsh hospital. J. Hosp Infect. 2007;66:352-9.

2. Cooper RA, Griffith CJ, Malik RE, et al. Monitoring the effectiveness of cleaning in four British hospitals. Am J Infect Control. 2007:35:338 - 41. 
3. Griffith CJ, Cooper RA, Gilmore J,et al. An evaluation of hospital cleaning regimes and standards. J. Hosp Infect. 2000;45:19-28.

4. Frota OP, Ferreira AM, Rigotti MA, et al. Effectiveness of clinical surface cleaning and disinfection: evaluation methods. Rev Bras Enferm. 2020; doi:10.1590/0034-7167-2018-0623.

5. Omidbakhsh $N$, Ahmadpour F, Kenny N. How reliable are ATP bioluminescence meters in assessing decontamination of environmental surfaces in healthcare settings? PLoS One. 2014; doi:10.1371.

6. Branch-Elliman W, Robillard E, McCarthy $G \mathrm{~J} r$, et al. Direct feedback with the ATP luminometer as a process improvement tool for terminal cleaning of patient rooms. Am J Infect Control. 2014; doi:10.1016/j.ajic.2013.08.012.

7. Smith PW, Beam E, Sayles $H$, et al. Impact of adenosine triphosphate detection and feedback on hospital room cleaning. Infect Control Hosp Epidemiol. 2014; doi:10.1086/675839.

8. Hayden MK, Bonten MJ, Blom DW, et al. Reduction in acquisition of vancomycin-resistant enterococcus after enforcement of routine environmental cleaning measures. Clin Infect Dis. 2006;42:1552-60.

9. van Arkel A, Willemsen I, Kilsdonk-Bode L, et al. ATP measurement as an objective method to measure environmental contamination in 9 hospitals in the Dutch/Belgian border area. Antimicrob Resist Infect Control. 2020; doi:10.21203/rs.2.18947/v2.

10. Willemsen I, Kluytmans J. The infection risk scan (IRIS): standardization and transparency in infection control and antimicrobial use. Antimicrob Resist Infect Control. 2018; doi:10.1186/s13756018-0319-z

11. Lewis T, Griffith C, Gallo M, et al. A modified ATP benchmark for evaluating the cleaning of some hospital environmental surfaces. J. Hosp Infect. 2008; doi:10.1016/j.jhin.2008.03.013.

12. Amin SR, Folkert CM, Erie JC. Assessing the effectiveness of surface cleaning methods in intravitreal injection procedure rooms. Ophthalmology. 2014; doi:10.1016/j.ophtha.2013.08.006.

13. Boyce JM, Havill NL, Havill HL, et al. Comparison of fluorescent marker systems with 2 quantitative methods of assessing terminal cleaning practices. Infect Control Hosp Epidemiol. 2011; doi:10.1086/662626.

14. Moore G, Smyth D, Singleton J, et al. The use of adenosine triphosphate bioluminescence to assess the efficacy of a modified cleaning program implemented within an intensive care setting. Am J Infect Control. 2010; doi:10.1016/j.ajic.2010.02.011.

15. Smith PW, Beam E, Sayles $H$, et al. Impact of adenosine triphosphate detection and feedback on hospital room cleaning. Infect Control Hosp Epidemiol. 2014; doi:10.1086/675839.

16. Wilkinson MD, Dumontier $M$, Aalbersberg IJ, et al. The FAIR guiding principles for scientific data management and stewardship. Sci Data 2016; doi:10.1038/sdata.2016.18.

\section{Figures}




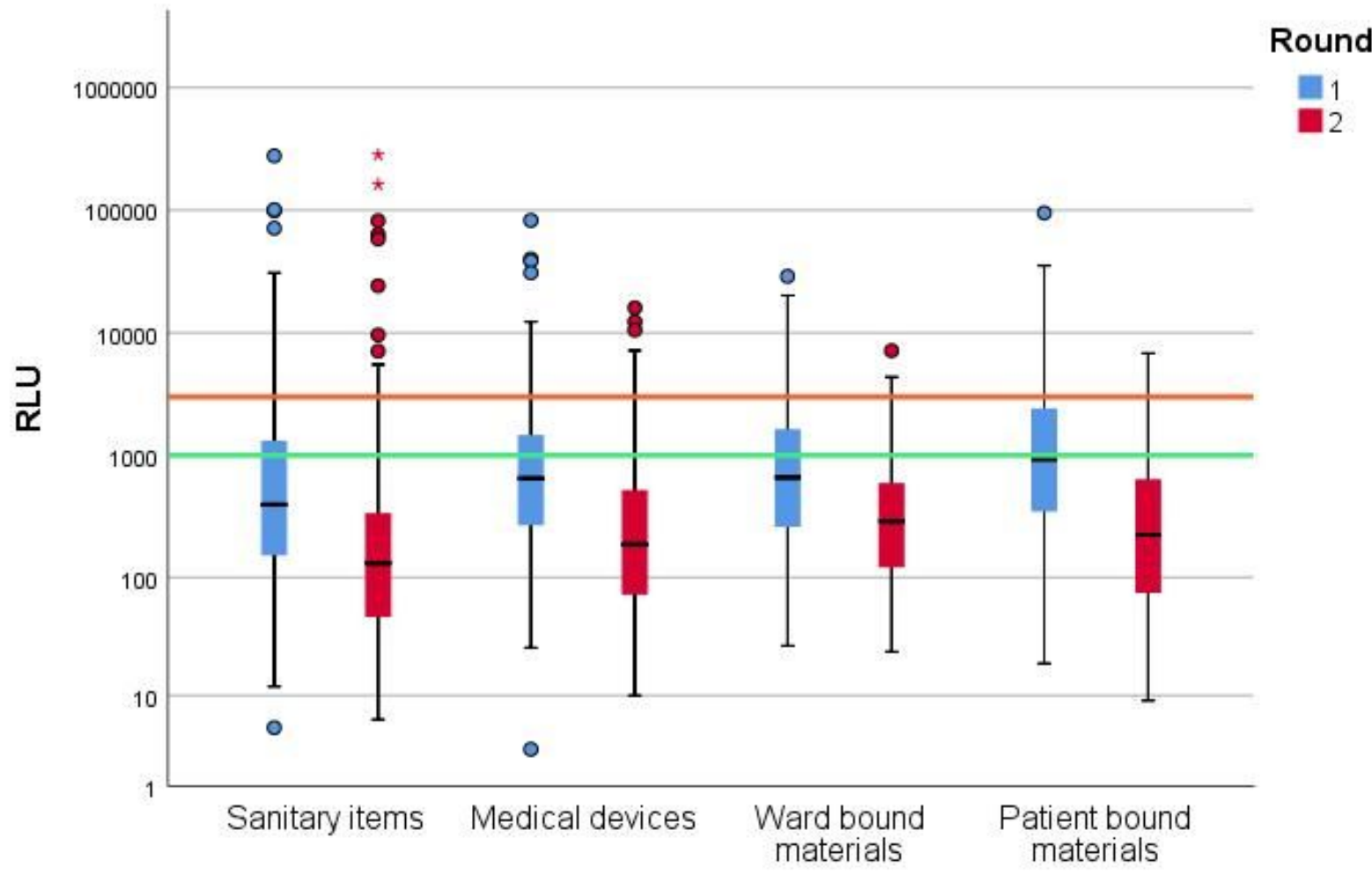

Figure 1

Boxplot of differences between both rounds of measurement. Outliers are marked with a circle, extreme outliers with a star. RLU breakpoints are marked with colored lines. 


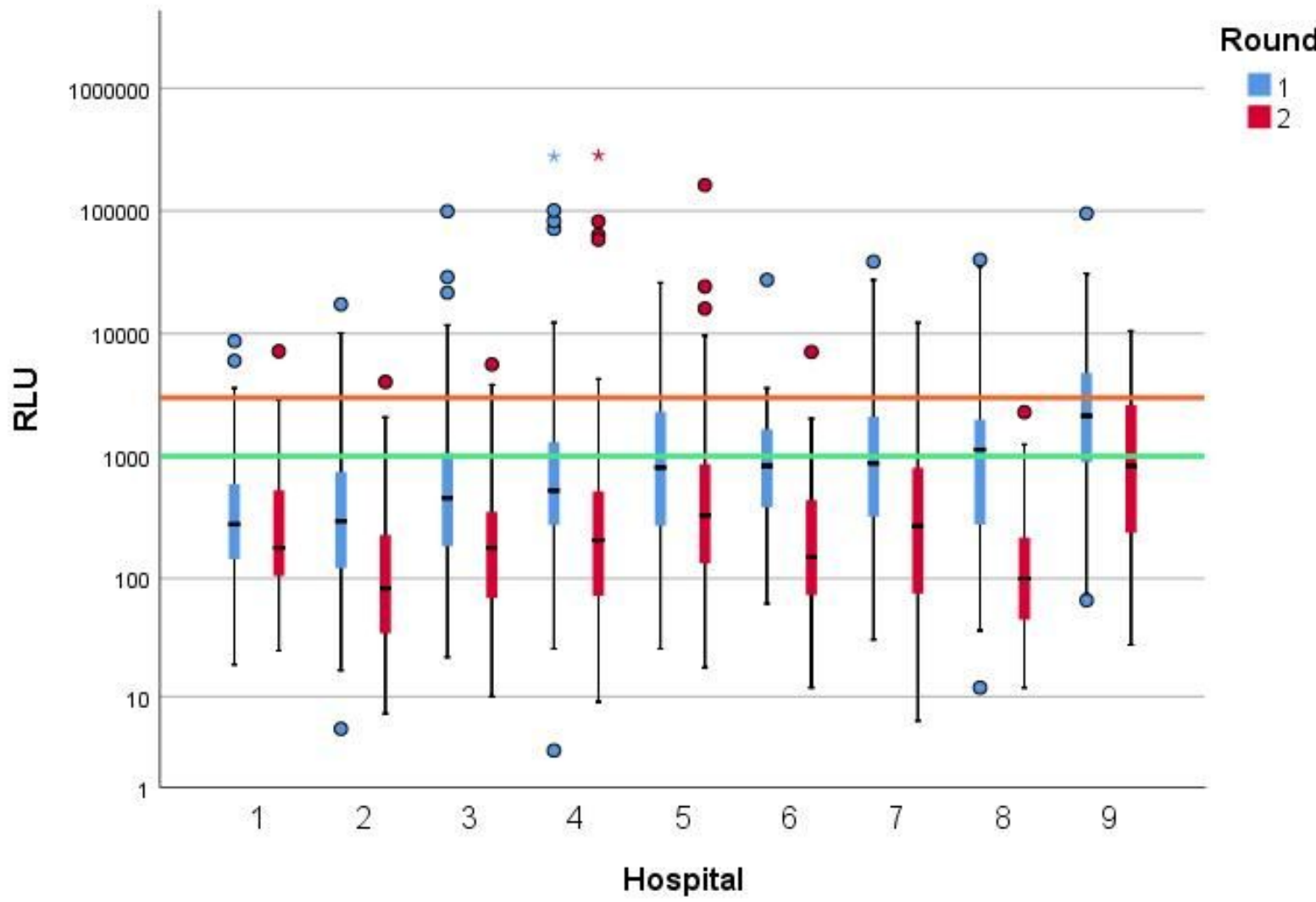

Figure 2

Boxplot of RLU values between hospitals for each round of measurement. Outliers are marked with a circle, extreme outliers with a star. RLU breakpoints are marked with colored lines. 


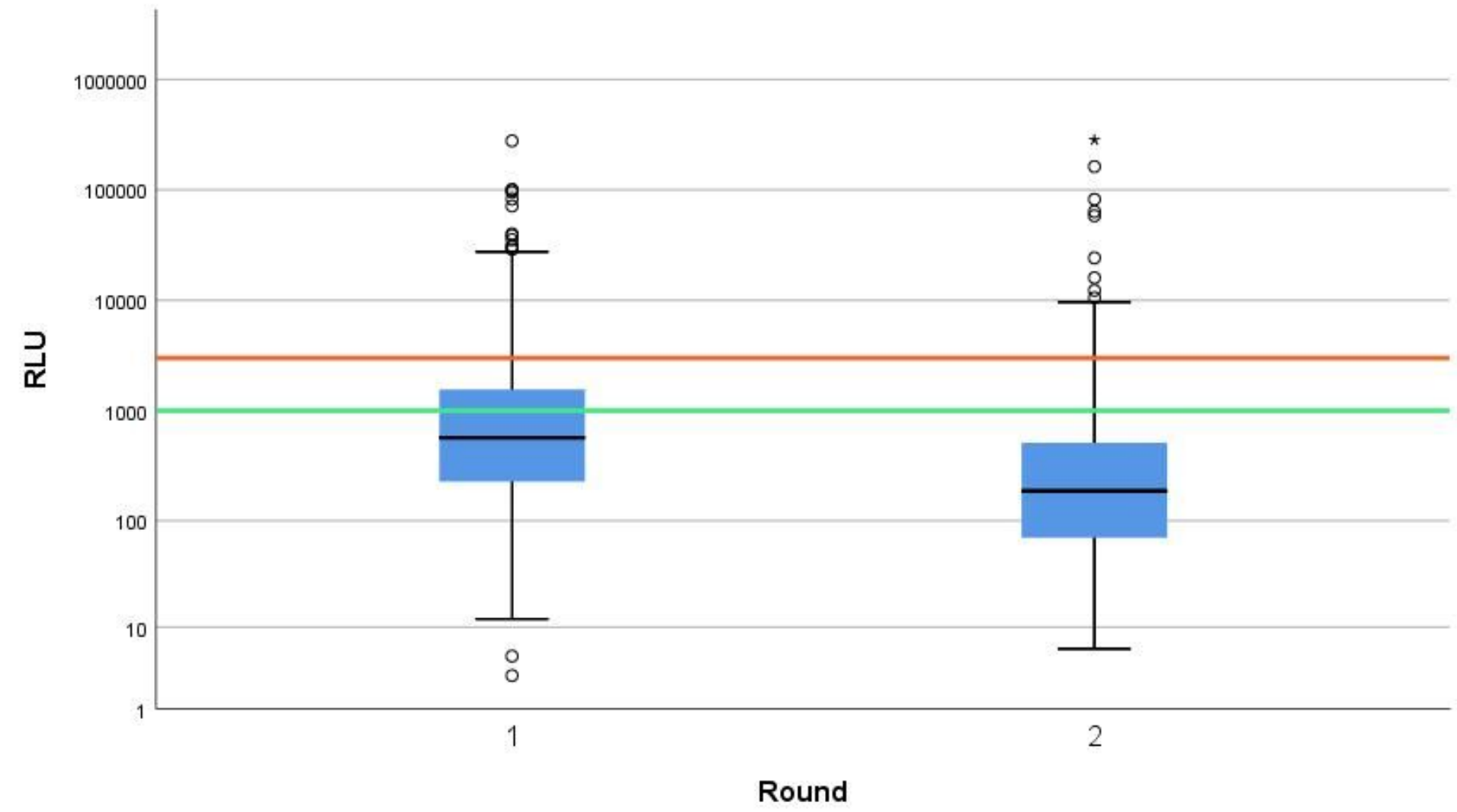

Figure 3

Boxplot of RLU values between fomite groups for each round of measurement. Outliers are marked with a circle, extreme outliers with a star. RLU breakpoints are marked with colored lines. 